\title{
The surface energy balance of a polygonal tundra site in northern Siberia - Part 2: Winter
}

\author{
M. Langer, S. Westermann, S. Muster, K. Piel, and J. Boike \\ Alfred-Wegener-Institute for Polar and Marine Research, Telegrafenberg A43, 14473 Potsdam, Germany
}

Received: 5 August 2010 - Published in The Cryosphere Discuss.: 25 August 2010

Revised: 11 April 2011 - Accepted: 19 May 2011 - Published: 14 June 2011

\begin{abstract}
In this study, we present the winter time surface energy balance at a polygonal tundra site in northern Siberia based on independent measurements of the net radiation, the sensible heat flux and the ground heat flux from two winter seasons. The latent heat flux is inferred from measurements of the atmospheric turbulence characteristics and a model approach. The long-wave radiation is found to be the dominant factor in the surface energy balance. The radiative losses are balanced to about $60 \%$ by the ground heat flux and almost $40 \%$ by the sensible heat fluxes, whereas the contribution of the latent heat flux is small. The main controlling factors of the surface energy budget are the snow cover, the cloudiness and the soil temperature gradient. Large spatial differences in the surface energy balance are observed between tundra soils and a small pond. The ground heat flux released at a freezing pond is by a factor of two higher compared to the freezing soil, whereas large differences in net radiation between the pond and soil are only observed at the end of the winter period. Differences in the surface energy balance between the two winter seasons are found to be related to differences in snow depth and cloud cover which strongly affect the temperature evolution and the freeze-up at the investigated pond.
\end{abstract}

\section{Introduction}

In scenarios of the future climate obtained from current stateof-the-art General Circulation Models (GCMs), the Arctic experiences a much more pronounced warming compared to the global average. The strongest warming is expected to occur during winter which is already confirmed in current climate observations (Moritz et al., 2002; Johannessen et al.,

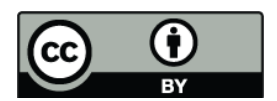

Correspondence to: M. Langer (moritz.langer@awi.de)
2004). This warming trend is already reflected in widely increasing soil temperatures in arctic land areas underlain by permafrost (e.g. Osterkamp, 2005).

The diversity and complexity of the processes governing the arctic climate constitute a major challenge for climate modeling, so that predictions are associated with a great uncertainty. The scientific report of the "Arctic Climate Impact Assessment" concludes that "much of the uncertainty in arctic climate change projections can be attributed to an insufficient knowledge of many of the physical processes active in the arctic domain. [...] To validate coupled high-resolution models in the Arctic, improved and extended observational datasets are required. In situ observations exist for a few locations and restricted time periods, but more such datasets are needed." (ACIA, 2004). The latter is especially true for field datasets on the heat and moisture turnover at the land-atmosphere interface, which must be parameterized in an adequate way in climate models. For sea ice on the Arctic Ocean, the SHEBA study has compiled a comprehensive dataset on the surface energy balance (Persson et al., 2002), which has been used extensively for model validation (e.g. Beesley et al., 2000; Tjernstrom et al., 2005). For arctic land areas, Westermann et al. (2009) documented the annual course of the surface energy balance for a permafrost site on Svalbard, which, however, is not representative for the vast permafrost regions in Siberia, Canada or Alaska. So far this study is the only available study on the annual surface energy balance in northern Siberia.

Arctic Permafrost has received increased attention through scenarios, which suggest massive emissions of greenhouse gases due to microbial decomposition of organic material that thaws in the course of permafrost degradation. Permafrost models driven by the output of climate models (GCM's) predict a sizable reduction of the permafrost area until 2100 and an increase of the active layer thickness in the remaining area (e.g. Stendel and Christensen, 2002;

Published by Copernicus Publications on behalf of the European Geosciences Union. 

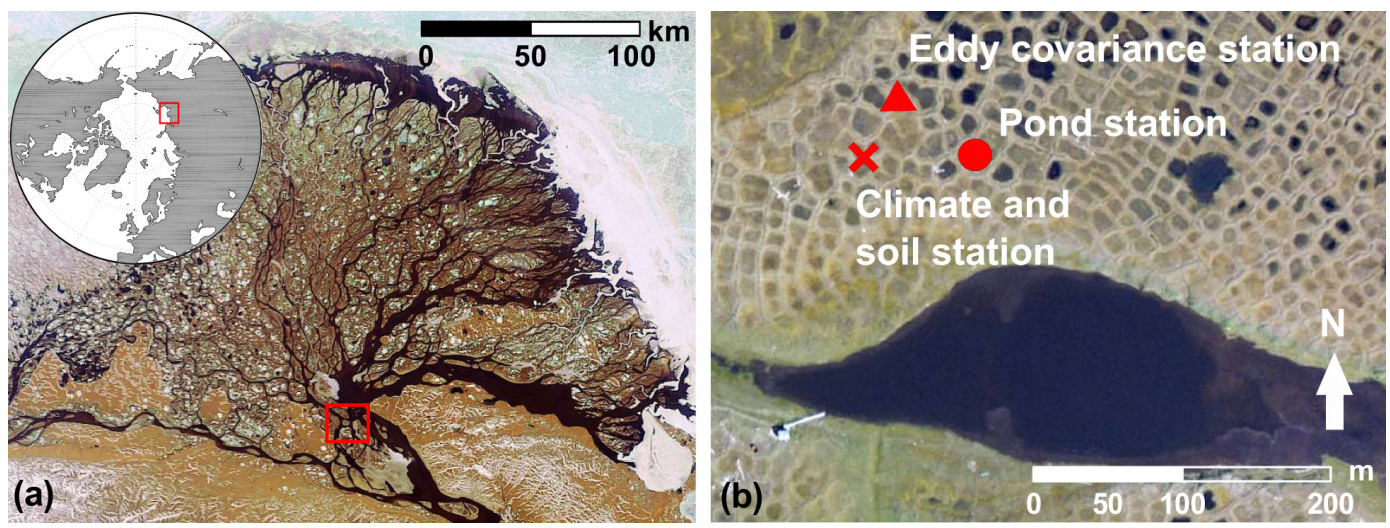

Fig. 1. (a) Location of the study site $\left(72^{\circ} 22^{\prime} \mathrm{N} ; 126^{\circ} 30^{\prime} \mathrm{E}\right)$ in the Lena River Delta on a Envisat (MERIS) image acquired on 15 June 2006 (ESA, 2006). (b) Location of the measurement stations at the study site on Samoylov Island.

Lawrence and Slater, 2005; Nicolsky et al., 2007; Lawrence et al., 2008). In order to improve the accuracy of such projections, it is desirable to obtain more regional datasets that can characterize the physical processes and serve as model validation.

This study is the second part of an extensive investigation on the annual surface energy balance at a polygonal tundra site in northern Siberia, which represents the first effort of that scope in the vast tundra regions of northern Siberia. While the first part (Langer et al., 2011) focuses on the summer time energy balance and its spatial variability induced by heterogeneities in the polygonal tundra, this study focuses on the surface energy balance during the winter periods from 1 October 2007 until 30 March 2008, and 1 October 2008 until 30 March 2009. The objectives of the study are to (i) identify the controlling and limiting factors of the winter time surface energy balance, (ii) evaluate differences in the surface energy balance between the most prominent landscape elements, namely the snow-covered tundra soils and freezing water bodies, and (iii) assess differences between the two winter seasons. The results are discussed with respect to modeling the arctic boundary layer and permafrost.

\section{Study site}

The study site is located at the southern part of the Lena River Delta on Samoylov Island $\left(72^{\circ} 22^{\prime} \mathrm{N} ; 126^{\circ} 30^{\prime} \mathrm{E}\right)$ (Fig. 1). The regional climate is arctic-continental with a mean annual air temperature (MAAT) of about $-13^{\circ} \mathrm{C}$, a pronounced annual temperature amplitude of about $60^{\circ} \mathrm{C}$ and a total annual precipitation around $250 \mathrm{~mm}$ (Boike et al., 2008). Snow fall and refreezing of the soil begins towards the end of September. The polar winter lasts from mid November until end of January. The climate and synoptic conditions during the winter are largely determined by the Siberian High causing air temperatures to fall frequently below $-45^{\circ} \mathrm{C}$. The high pressure system is often disturbed by the influx of cyclones with high intensity and short lifetime (Zhang et al., 2004). The continental climate conditions are also reflected in the thermal regime of the soil, which is characterized by continuous permafrost reaching depths of 500 to $600 \mathrm{~m}$ in the region of Lena River Delta (Grigoriev, 1960). During the observation period, the soil temperature is about $-10^{\circ} \mathrm{C}$ at the depth of the zero annual amplitude $(\mathrm{ZAA} \approx 15 \mathrm{~m})$ and the maximum thaw depth ranges from 0.4 to $0.5 \mathrm{~m}$ at the study site (Langer et al., 2011). The tundra surface is highly fractionated due to polygonal structures typically 50 to $100 \mathrm{~m}^{2}$ large. The rims of these polygons are elevated by about 0.2 to $0.5 \mathrm{~m}$ compared to the centers. The polygonal centers consist of water-saturated peat soils or constitute ponds which frequently occur at the study site. During the winter period, the tundra soils are covered by a shallow snow layer, which has been observed to persist from October until May (Boike et al., 2008).

\section{Methods}

The equation of the surface energy balance can be written as

$Q_{\text {net }}=Q_{\mathrm{H}}+Q_{\mathrm{E}}+Q_{\mathrm{G}}+Q_{\text {melt }}+C$,

where $Q_{\text {net }}$ is the net radiation, $Q_{\mathrm{H}}$ the turbulent sensible heat flux, $Q_{\mathrm{E}}$ the turbulent latent heat flux, $Q_{\mathrm{G}}$ the subsurface (ground or snow) heat flux, $Q_{\text {melt }}$ the energy consumed by the melting of snow, and $C$ is the residual of the energy balance which accounts for inaccuracies of measurement. In the following the term $Q_{\text {melt }}$ is neglected, since only temperatures well below the freezing point are observed. The energy consumed by sublimation of snow is accounted for by the latent heat flux $Q_{\mathrm{E}}$.

For the evaluation of the surface energy balance we distinguish two basic landscape features: the snow covered tundra soils and freezing or frozen water bodies. While the entire surface energy balance is measured at the snow covered tundra (hereafter referred to as tundra site), only the net radiation 
$Q_{\text {net,p }}$ and the ground heat flux $Q_{\mathrm{G}, \mathrm{p}}$ are gathered at a freezing polygonal pond (hereafter referred to as pond site).

\subsection{Radiation balance}

The net radiation at the tundra $Q_{\text {net }}$ and the pond sites $Q_{\text {net,p }}$ is measured with net radiation sensors (NR-Lite, Kipp \& Zonen, Netherlands). Based on studies which compare the applied NR-Lite sensor with single component sensors of higher accuracy we assume the relative accuracy to be about $20 \%$ of the measured value (Brotzge and Duchon, 2000; Kohsiek et al., 2007). Data from the NR-Lite sensor are not available at the tundra site for the winter 2008-2009. Instead we apply a four-component radiation sensor (CNR1, Kipp \& Zonen, Netherlands) to calculate the net radiation. According to instrument specification this senor features a relative accuracy of about $10 \%$. The outgoing thermal radiation at the tundra site is measured separately by a long-wave radiation sensor (CG1, Kipp \& Zonen, Netherlands) during winter 2007-2008. The relative accuracy of the sensor is assumed to be better than $10 \%$ according to a carefully designed sensor inter comparison (Obleitner and De Wolde, 1999). In winter 2008-2009, the outgoing long-wave radiation is calculated from an infrared surface temperature sensor (IRTS$\mathrm{P}$, Apogee Instruments, USA). The sensor delivers brightness temperatures in the spectral range from 7.5 to $14 \mu \mathrm{m}$ with an accuracy of about $\pm 0.5^{\circ} \mathrm{C}$ (Bugbee et al., 1998) from which the outgoing thermal radiation is calculated using Stephan-Boltzmann's law assuming isotropic sky-radiation (cf. Langer et al., 2011, Sect. 3.1). This results in an absolute accuracy of about $\pm 2 \mathrm{~W} \mathrm{~m}^{-2}$ for the upwelling thermal radiation in the relevant temperature range from 0 to $-45^{\circ} \mathrm{C}$. Furthermore, the real surface temperature $T_{\text {surf }}$ is calculated using a thermal emissivity of $0.99 \pm 0.01$ for snow (Dozier and Warren, 1982). This results in a total uncertainty of about $\pm 1^{\circ} \mathrm{C}$ on the surface temperature in the expected range of up- and down-welling radiation.

\subsection{Turbulent heat fluxes}

The sensible heat flux $Q_{\mathrm{H}}$ is inferred from the eddy covariance method. The applied eddy covariance setup consists of a 3-D sonic anemometer (C-SAT, Campbell Scientific, USA) and a data logger (CR3000, Campbell Scientific, USA). This measurement setup permits the sampling of the three dimensional wind speed components and the sonic temperature at a rate of $20 \mathrm{~Hz}$. Based on these measurements the momentum flux $u_{*}^{2}$ and, in first order approximation, the buoyancy flux $Q_{\mathrm{HB}}$ can be inferred (Liu et al., 2001). These turbulent fluxes are calculated for $30 \mathrm{~min}$ intervals with the "QA/QC" software package "TK2" including standard corrections and quality tests (Mauder and Foken, 2004; Mauder et al., 2008). For a more detailed description of the corrections and quality tests applied in the data post-processing please refer to the companion study (Langer et al., 2011, Sect. 3.2). In princi- ple, the buoyancy flux $Q_{\mathrm{HB}}$ must be corrected according to the flux of water vapor in order to obtain the true sensible heat flux $Q_{\mathrm{H}}$ (Schotanus et al., 1983). With an expected Bowen ratio of $Q_{\mathrm{H}} / Q_{\mathrm{E}} \approx 0.5$, the true sensible heat flux is less than $3 \%$ lower than the measured buoyancy flux in the temperature range from -10 to $-45^{\circ} \mathrm{C}$ and about $10 \%$ lower for a Bowen ratio of 2 at $0{ }^{\circ} \mathrm{C}$. Hence, we accept the buoyancy flux to be a good approximation of the real sensible heat flux for most of the observation period. According to a quality check and the exclusion of the lee wind sector $\left(263^{\circ}\right.$ to $\left.277^{\circ}\right)$, about $18 \%$ of the flux measurements must be discarded. In carefully designed experiments, the applied quality criterion is found to be associated with a relative accuracy of about $15 \%$ which we assume to be appropriate for the measured buoyancy flux (Mauder et al., 2006). In addition to the turbulent fluxes, the stability parameter $\zeta$ can be inferred from the eddy covariance measurements, which provide information about the atmospheric stratification with $\zeta \approx 0$ for a well mixed or neutrally stratified atmosphere, $\zeta>0$ for stable, and $\zeta<0$ for unstable atmospheric stratifications.

The latent heat flux $Q_{\mathrm{E}}$ at the tundra site is modeled for winter 2007-2008 by the same approach which is described in detail in the companion study during the summer half-year (cf. Langer et al., 2011, Appendix D). The model makes use of the available eddy covariance measurements of the momentum flux $u_{*}^{2}$ and the buoyancy flux $Q_{\mathrm{HB}}$, from which the turbulent transport coefficient is inferred. The atmospheric stratification is calculated based on the often applied parametrization introduced by Høgstrøm (1988). The near surface gradient of the specific humidity is inferred from measurements of relative humidity RH in $2 \mathrm{~m}$ height and the surface temperature $T_{\text {surf }}$ from which the water vapor pressure above the snow surface is calculated using Magnus formula. The relative accuracy of the latent heat flux is estimated to be on the order of $25 \%$, assuming Gaussian error propagation with a relative accuracy of $15 \%$ on the transport coefficient (inferred from the eddy measurements) and $20 \%$ on the gradient of the specific humidity.

\subsection{Ground heat fluxes}

The ground heat flux is calculated for both sites. The ground heat flux is defined as the heat flux across the landscape surface which, as appropriate, is the soil, the snow, or the lake ice surface. For the heat flux calculations, we apply the calorimetric and the conductive method (cf. Langer et al., 2011, Appendix B and C).

\subsubsection{The calorimetric method}

The calorimetric method calculates the ground heat flux based on changes in the internal energy of a soil column using measurements of the soil temperature and liquid water content $\theta_{\mathrm{w}}$ (cf. Langer et al., 2011, Appendix B). This method is used for evaluating averages of the ground heat 


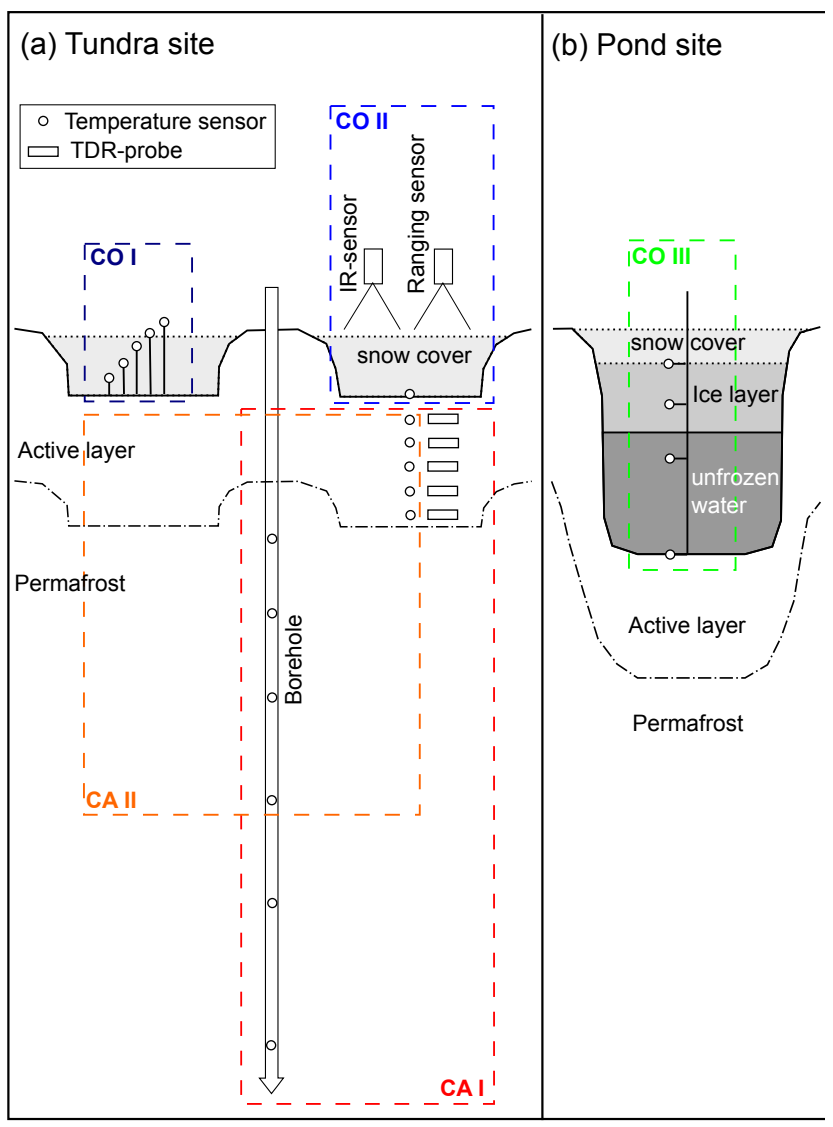

Fig. 2. Scheme of the different measurement setups used for the evaluation of ground heat flux. (a) Cross-section of the tundra soil indicating polygonal rims and centers. (b) Cross-section of the polygonal pond during the stage of freezing. Note that the depicted scheme is not to scale.

flux over periods longer than a few days. Due to the measurements of temperature and liquid water content, it is possible to distinguish sensible and latent heat storage, which we express as energy fluxes $Q_{\mathrm{G} \text {, sensible }}$ and $Q_{\mathrm{G} \text {, latent }}$. Note that the heat storage in the shallow snow layer becomes negligible for long-term averages, so that temperature profiles in the snow pack are not required. During winter 2007-2008, soil temperatures are available from a $26 \mathrm{~m}$ borehole and a thermistor profile in the active layer (CA I) (Fig. 2). The liquid water content $\theta_{\mathrm{w}}$ is measured in the active layer by Time-DomainReflectometry (TDR) probes.

Since the deep borehole and the TDR probes are not available during winter 2008-2009 (CA II), we rely on a shallow borehole of $4 \mathrm{~m}$ depth and a parameterization of the liquid water content in dependence of the soil temperature. This so-called "freeze curve" is inferred by fitting a polynomial function to measurements of water content and temperature of the previous year (Fig. 3). In both years (before the onset of freezing) the soils are water saturated featuring a volumetric liquid water content of about $75 \%$. During freezing,

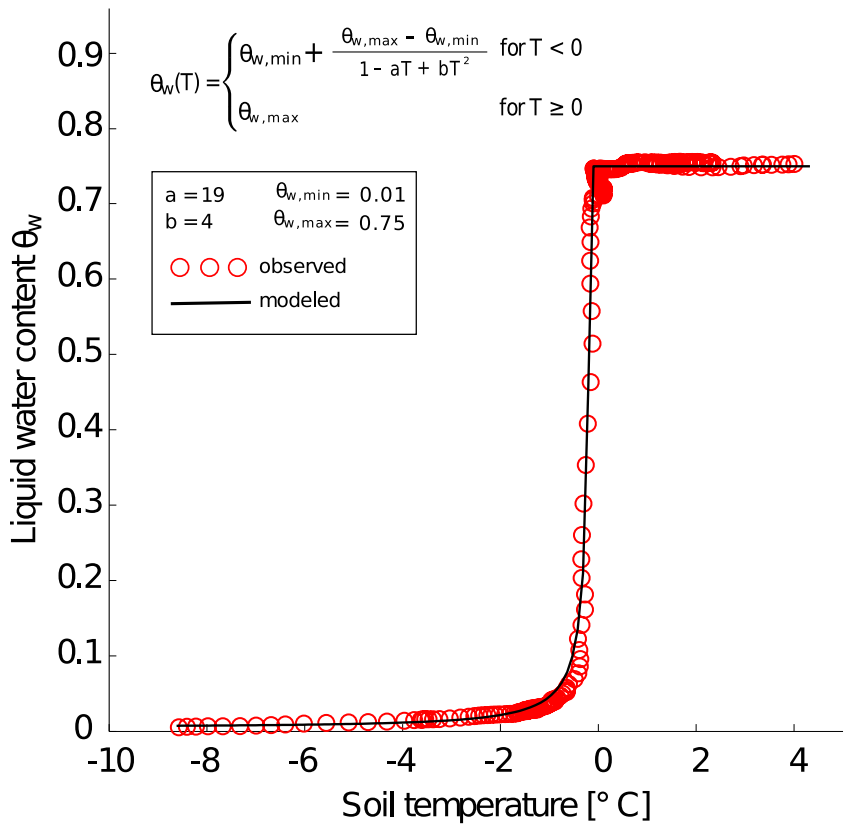

Fig. 3. The freezing characteristic of the soil at the study site which parameterizes the soil water content $\theta_{\mathrm{W}}$ in dependence to the soil temperature. The used polynomial function and the fitted parameters are depicted in the figure.

we assume the peat soils to stay saturated, since subsurface drainage is assumed to be negligible. In addition, the vertical water exchange is largely impeded by the formation of an ice layer at the soil surface with the beginning of freezing. Hence, it can be assumed that changes in the liquid water content are mainly attributed to the phase change of water during the observation period.

The calorimetric method requires measurements down to a depth of zero temperature change in the concerned averaging period. Hence, heat fluxes below the measurement depth of $4 \mathrm{~m}$ are required. We calculate the heat flux through the lower boundary of the temperature profile by using the conductive method (cf. Langer et al., 2011, Appendix C). Soil heat capacities, thermal diffusivity and heat conductivity of frozen tundra soils are evaluated similar to the summer time values (Table 1).

\subsubsection{The conductive method}

The conductive method calculates the heat flux across a layer by solving the differential equation of conductive heat transport. For more details on the calculations please refer to the companion study (Langer et al., 2011, Appendix C). The conductive method involves the determination of the thermal diffusivity of snow or soil which are presented in Table 1. The method is applied for both calculations of the ground heat flux at (a) the tundra site and (b) the thermokarst pond. 
Table 1. Used soil parameters for ground heat flux calculations during the winter period. Values of porosity $P_{\text {dry }}$ and volumetric ice content $\theta_{\mathrm{i}}$ are estimated based on soil sample analysis and in situ soil water content measurements during summer. The heat capacities are calculated by weighting $C_{\mathrm{h}, \mathrm{i}}$ and $C_{\mathrm{h}, \mathrm{s}}$ according to the assumed ice content and porosity. The thermal diffusivities $D_{\mathrm{h}}$ are determined by using the conductive method, from which we evaluate the thermal conductivity $K_{\mathrm{h}}$ with estimated heat capacity (cf. Langer et al., 2011). Errors are calculated using Gaussian error propagation.

\begin{tabular}{lccccc}
\hline Substrate & $P_{\text {dry }}$ & $\theta_{\mathrm{i}}$ & $C_{\mathrm{h}}\left[\mathrm{MJ} \mathrm{m}^{-3} \mathrm{~K}^{-1}\right]$ & $D_{\mathrm{h}}\left[\mathrm{m}^{2} \mathrm{~s}^{-1}\right] \times 10^{-6}$ & $K_{\mathrm{h}}\left[\mathrm{W} \mathrm{m}^{-1} \mathrm{~K}^{-1}\right]$ \\
\hline frozen dry peat & $0.8 \pm 0.1$ & $0.1 \pm 0.1$ & $0.7 \pm 0.30$ & $0.68 \pm 0.19$ & $0.46 \pm 0.25$ \\
frozen wet peat & $0.8 \pm 0.1$ & $0.7 \pm 0.1$ & $1.8 \pm 0.30$ & $0.54 \pm 0.09$ & $0.95 \pm 0.23$ \\
frozen saturated peat & $0.8 \pm 0.1$ & $0.8 \pm 0.1$ & $2.0 \pm 0.05$ & $0.96 \pm 0.09$ & $1.92 \pm 0.19$ \\
snow & $\rho_{\text {snow }}=190 \pm 10 \mathrm{kgm}^{-3}$ & $0.4 \pm 0.04$ & $0.54 \pm 0.04$ & $0.22 \pm 0.03$ \\
ice & $\rho_{\text {ice }}=920 \mathrm{kgm}^{-3}$ & 1.9 & 1.2 & 2.3 \\
\hline
\end{tabular}

a. For the tundra site, this method is applied for calculating heat fluxes with hourly resolution. These high resolution heat fluxes are only obtained at polygonal centers, where snow cover measurements are available. Two different sets of measurements (CO I and CO II) are used to calculate the heat flux across the snow cover with the conductive method (Fig. 2). Firstly, snow temperature measurements at three depths with known relative distance are employed. This method is similar to the conductive heat flux calculation used for the uppermost soil layer in the companion study and involves the determination of the thermal diffusivity of the snow cover. The required snow temperature profile measurements are available during winter 2008-2009. The used measurement setup (CO I) consists of an array of temperature sensors (thermocouples) fixed on very thin $(4 \mathrm{~mm})$ carbon rods of different length which are placed vertically about $3 \mathrm{~cm}$ apart from each other (Fig. 2). The height difference between the temperature sensors is $5 \mathrm{~cm}$. Secondly, for winter 2007-2008 when the snow temperature profile is not available, the snow heat flux is calculated using the surface temperature of the snow cover, the temperature at the snow-soil interface, the snow depth and the thermal diffusivity and conductivity of the snow cover (CO II). The snow surface temperature is measured by an infrared sensor, the temperature at the snow-soil interface is measured by a thermistor close to the surface and the required snow depth is obtained by an ultrasonic ranging sensor (Fig. 2). As a rough approximation, we assume a similar thermal diffusivity of the snow cover in winter 2007-2008, as calculated from the temperature profile measurements during winter 2008-2009.

b. For the pond site the conductive method is used to calculate long-term averages of the heat flux through the ice layer $Q_{\mathrm{G}, \mathrm{p}}$. The employed temperature profile (CO III) consists of four temperature sensors which are fixed on a mast located in the middle of the water body, where the water depth is approximately $0.8 \mathrm{~m}$ (Fig. 2). In the course of the winter, the temperature sensors freeze in the ice of the pond. From the temperature profile, we can calculate the heat flux trough the ice layer, as soon as it approaches a thickness of $24 \mathrm{~cm}$, which then contains the two uppermost temperature sensors of the profile. We use the conductive method described in Langer et al. (2011) (cf. Appendix C) to evaluate the heat flux through the ice cover surface with the known thermal diffusivity and conductivity of ice. The employed values are depicted in Table 1.

\subsection{Snow cover measurements}

We use different methods for the detection of the snow depth. The snow depth is measured with an ultrasonic ranging sensor (SR50, Campbell Scientific, USA) located at the tundra site and the pond site. During winter 2008-2009, data from the ultrasonic sensor is not available at the tundra site. Therefore, we infer the snow depth from the snow temperature profile described in Sect. 3.3 using the method of Lewkowicz (2008), who determines the snow depth from a temperature decoupling between buried and unburied sensors. The temperature profile provides a vertical resolution of $5 \mathrm{~cm}$. The method is found to deliver a suitable measure of the snow cover evolution compared to standard observations at climate stations (Lewkowicz, 2008). In addition, we use the AMSRE 5-Day L3 snow water equivalent (SWE) product (Kelly et al., 2004) to obtain a complementary snow cover information in addition to our point measurements. The satellite product is based on passive microwave detection and features a spatial resolution of $25 \mathrm{~km}$. A detailed technical description of the product and the retrieval algorithm is given by Pulliainen and Hallikainen (2001). For tundra surfaces, the accuracy of the SWE product is expected to be in the range of $10 \%$, since the shallow vegetation only marginally affects the snow cover signal (Foster et al., 2005). We selected the closest pixel to the study site, which must be understood as an average value over a large variety of surface structures. The remote sensing product supports the evaluation of the snow depth measurements, as the satellite data 
allow to judge whether the point observations reflect a local or regional snow cover evolution.

Moreover, SWE field measurements are conducted during April 2008 and 2009. From these measurements, we calculate the snow heat capacity, which is used for the heat flux calculations. The obtained values are presented in Table 1. The field measurements of the snow density $\rho_{\text {snow }}$ are further used for the conversion of the AMSR-E dataset from SWE to snow depths.

\section{Results}

In the following, we describe the winter surface energy balance. We divide the observation period into three sections, according to the availability of sunlight. During the first and the last winter sections, short-wave radiation is still or again present, whereas the middle period is characterized by the absence of sunlight due to polar night conditions.

\subsection{Early winter (1 October-30 November)}

The first winter period lasts from the beginning of October until the end of November, immediately before the beginning of the polar night. The surface energy balance is characterized by a strongly negative net radiation on the order of $-20 \mathrm{~W} \mathrm{~m}^{-2}$, which is about $25 \mathrm{~W} \mathrm{~m}^{-2}$ less compared to the preceding fall season (cf. Langer et al., 2011). The net short-wave radiation is very small $\left(\approx 2 \mathrm{~W} \mathrm{~m}^{-2}\right)$ due to the high albedo of the snow cover. The negative net radiation is largely balanced by the ground heat flux $Q_{\mathrm{G}}(-10$ to $-20 \mathrm{~W} \mathrm{~m}^{-2}$ ), whereas the sensible heat flux $Q_{\mathrm{H}}$ shows only a marginal contribution of about $-5 \mathrm{~W} \mathrm{~m}^{-2}$, which is only slightly more negative than during the fall season. The modeled latent heat flux $Q_{\mathrm{E}}$ is still positive $\left(\approx 10 \mathrm{~W} \mathrm{~m}^{-2}\right)$, which agrees with the high values measured in the previous fall period. Similar to the fall period, the energy balance residual $C$ is considerable (50\% of $Q_{\text {net }}$ ), which indicates that some heat flux is not detected.

The general weather conditions are characterized by rapidly declining air temperatures, decreasing sun angles, snow accumulation and the freezing of soil and water bodies. In both years, the air temperatures rapidly fall from about $0^{\circ} \mathrm{C}$ at the beginning to $-20^{\circ} \mathrm{C}$ at the end of the period. The build-up of a continuous snow cover starts in both winters at the beginning of October. However, differences in the snow depth evolution between both years are observed at the tundra site. In 2007, the snow cover reaches a depth of about $0.15 \mathrm{~m}$ shortly after the first snow fall and remains almost constant until the end of the period. In 2008, the snow cover accumulation is much slower and ends up with a snow depth of about $0.1 \mathrm{~m}$ (Fig. 4). An even greater difference in snow depth between the two winter seasons is observed at the pond site, which in 2007 is covered by about $0.2 \mathrm{~m}$ of snow shortly after the first snow fall, whereas in 2008 almost no snow cover is measured until the end of this winter period (Fig. 4). The differences in snow cover accumulation between the two winter seasons broadly agree with the satellite measurements (AMSR-E) (Fig. 4).

The net radiation of the first winter period is dominated by the long-wave radiation $\Delta Q_{\mathrm{L}}$, which in 2008 is about fifteen times larger than the net short-wave radiation $\Delta Q_{\mathrm{S}}$ (Table 2, Fig. 5). The incoming long-wave radiation steadily decreases from about $300 \mathrm{~W} \mathrm{~m}^{-2}$ to $180 \mathrm{~W} \mathrm{~m}^{-2}$. This general trend is overlain by rapid variations in the range of 60 to $70 \mathrm{~W} \mathrm{~m}^{-2}$. In frequent situations, the outgoing and the incoming longwave radiation are in quasi-balance $\left(Q_{\text {net }} \approx 0\right)$. The outgoing long-wave radiation follows the general trend of its incoming counterpart and decreases from about $315 \mathrm{~W} \mathrm{~m}^{-2}$ to $200 \mathrm{~W} \mathrm{~m}^{-2}$, which corresponds to a surface temperature cooling from 0 to $-24{ }^{\circ} \mathrm{C}$. The surface temperature of 2008 appears to be slightly increased compared to 2007, which on average amounts to an increased radiative loss on the order of $5 \mathrm{~W} \mathrm{~m}^{-2}$ in 2008 . The surface temperature follows to a large extent the short-term fluctuations of the incoming longwave radiation. The observed fluctuations are on the order of $10^{\circ} \mathrm{C}$. The negative net radiation is partly balanced by the sensible heat flux $Q_{\mathrm{H}}$, which is negative in both years. In both years, the average values of the sensible heat fluxes are small compared to the ground heat fluxes, but show strong short-term variations on the order of $30 \mathrm{~W} \mathrm{~m}^{-2}$. The observed fluctuations in the sensible heat fluxes largely follow the stepwise variations of the net radiation. Slightly positive sensible heat fluxes, that drag heat from the surface to the atmosphere, are observed occasionally. These events are strictly correlated to high values of down-welling thermal radiation and positive temperature gradients between the surface and the near-surface air temperature. High absolute values of the sensible heat flux are almost always associated with high wind speeds and strong turbulent exchange. The atmospheric stratification is mostly neutral $(\zeta \approx 0)$, while stable stratification $(\zeta>0)$ only occur occasionally under clearsky and calm conditions. Such stable stratifications are characterized by a very high ground heat flux, which compensates for the reduced sensible heat flux. The largest fraction of the negative net radiation is balanced by the ground heat flux $Q_{\mathrm{G}}$, which is predominately supplied by latent heat of freezing (Table 2). In the inter-annual comparison, the ground heat flux of 2008 is by a factor of about two increased compared to 2007. This difference corresponds to lower surface temperatures and the faster snow cover build-up of 2007 (Table 2). It also agrees with the fact, that the active layer is completely frozen by the end of the early winter period in 2008, but not in 2007.

Even larger differences in the ground heat flux between both years are observed at the polygonal pond. According to the temperature profile measurements, we can estimate the ice cover thickness to be about $30 \mathrm{~cm}$ at the end of the early winter period in 2007 . In 2008, the temperature measurements indicate that the water body is completely 
Table 2. Averages of the net radiation $Q_{\text {net }}$, the net short-wave radiation $\Delta Q_{\mathrm{S}}$, the net long-wave radiation $\Delta Q_{\mathrm{L}}$, the sensible heat flux $Q_{\mathrm{H}}$,

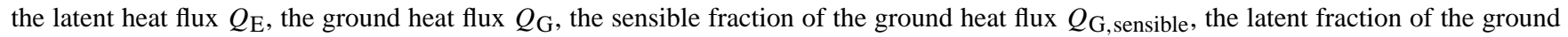
heat flux $Q_{\mathrm{G}, \text { latent }}$, and the closure term $C$. Turbulent heat fluxes marked in bold are affected by minor data gaps due to quality assessment or the exclusion of lee wind sectors. Furthermore, averages of the net radiation $Q_{\text {net,p }}$ and the ground heat flux $Q_{\mathrm{G}, \mathrm{p}}$ at the pond site are provided.

\begin{tabular}{|c|c|c|c|c|c|c|}
\hline & \multicolumn{2}{|c|}{ Early winter } & \multicolumn{2}{|c|}{ Polar winter } & \multicolumn{2}{|c|}{ Late winter } \\
\hline & 2007 & 2008 & 2007-2008 & 2008-2009 & 2008 & 2009 \\
\hline & 1 Oct-30 Nov & 1 Oct-30 Nov & 1 Dec-30 Jan & 1 Dec-30 Jan & 1 Feb-30 Mar & 1 Feb-30 Mar \\
\hline$Q_{\text {net }}\left[\mathrm{W} \mathrm{m}^{-2}\right]$ & $-17^{1}$ & $-21^{2}$ & $-21^{1}$ & $-25^{2}$ & $-14.7^{1}$ & - \\
\hline$\Delta Q_{\mathrm{S}}\left[\mathrm{W} \mathrm{m}{ }^{-2}\right]$ & - & 1.5 & 0 & 0 & - & - \\
\hline$\Delta Q_{\mathrm{L}}\left[\mathrm{W} \mathrm{m}^{-2}\right]$ & - & -22 & -21 & -25 & - & - \\
\hline$Q_{\mathrm{H}}\left[\mathrm{W} \mathrm{m}^{-2}\right]$ & -6 & -5 & -9 & - & -10.3 & - \\
\hline$Q_{\mathrm{E}}\left[\mathrm{W} \mathrm{m}^{-2}\right]$ & $9^{3}$ & - & $4^{3}$ & - & $3^{3}$ & - \\
\hline$Q_{\mathrm{G}}\left[\mathrm{W} \mathrm{m}^{-2}\right]$ & -11 & -20 & -17 & -14 & -5.4 & -10.4 \\
\hline$Q_{\mathrm{G}, \text { sensible }}\left[\mathrm{W} \mathrm{m}^{-2}\right]$ & 3 & -3 & -14 & -14 & -5.4 & -10.4 \\
\hline$Q_{\mathrm{G}, \text { latent }}\left[\mathrm{W} \mathrm{m}^{-2}\right]$ & -14 & -17 & -3 & 0 & 0 & - \\
\hline$C\left[\mathrm{~W} \mathrm{~m}^{-2}\right]$ & -9 & - & -1 & - & 2 & - \\
\hline$Q_{\mathrm{H}} / Q_{\text {net }}$ & 0.35 & 0.24 & 0.43 & - & 0.70 & - \\
\hline$Q_{\mathrm{E}} / Q_{\mathrm{net}}$ & $-0.53^{3}$ & - & $-0.19^{3}$ & - & $-0.20^{3}$ & - \\
\hline$Q_{\mathrm{G}} / Q_{\text {net }}$ & 0.65 & 0.95 & 0.81 & 0.56 & 0.37 & - \\
\hline$C / Q_{\text {net }}$ & $0.53^{3}$ & - & $0.05^{3}$ & - & $-0.14^{3}$ & - \\
\hline$Q_{\mathrm{H}} / Q_{\mathrm{E}}$ & $-0.67^{3}$ & - & $-2.25^{3}$ & - & $-3.43^{3}$ & - \\
\hline$Q_{\text {net,p }}\left[\mathrm{W} \mathrm{m}^{-2}\right]$ & $-18^{1}$ & $-23^{1}$ & $-22^{1}$ & $-25^{1}$ & $-20^{1}$ & $-21.5^{1}$ \\
\hline$Q_{\mathrm{G}, \mathrm{p}}\left[\mathrm{W} \mathrm{m}^{-2}\right]$ & $-12^{4}$ & $-34^{4}$ & -32 & -28 & -12.6 & -22.3 \\
\hline$T_{\text {surf }}\left[{ }^{\circ} \mathrm{C}\right]$ & -16 & -15 & -29.9 & -29.7 & -25.9 & -35.5 \\
\hline$T_{\text {air }}\left[{ }^{\circ} \mathrm{C}\right]$ & -16.1 & -14.8 & -29.7 & -29.5 & -24.8 & -34.7 \\
\hline $\mathrm{RH}[\%]$ & 81 & - & 70 & - & 75 & - \\
\hline Snow depth [m] & 0.09 & 0.05 & 0.11 & 0.15 & 0.18 & - \\
\hline
\end{tabular}

${ }^{1}$ Radiation values measured with the NR-Lite sensor.

2 Values obtained with the CNR1 sensor.

3 Modeled latent heat fluxes.

${ }^{4}$ Subsurface heat fluxes estimated from ice cover thickness.

frozen down to a depth of $85 \mathrm{~cm}$. Assuming an ice density of about $920 \mathrm{~kg} \mathrm{~m}^{-3}$, this amount of ice corresponds to an average heat flux $Q_{\mathrm{G}, \mathrm{p}}$ of about $-12 \mathrm{~W} \mathrm{~m}^{-2}$ in 2007 and about $-34 \mathrm{~W} \mathrm{~m}^{-2}$ in 2008 . Note that these heat fluxes are only estimated according to the amount of frozen water, which does not contain the temperature change of the water body and the ground underneath. Hence, the true ground heat flux at the pond must be even larger. However, in 2007, the estimated heat flux value at the freezing pond is in a good agreement with the net radiation $Q_{\text {net,p }}$, which we measure directly at the surface of the water body (Table 2). It is evident, that such an energy balance agreement is not given in 2008, where the pond heat flux releases about $10 \mathrm{~W} \mathrm{~m}^{-2}$ more than is lost by radiation.

During the early winter period a residual term of the energy balance of $C=-9 \mathrm{~W} \mathrm{~m}^{-2}$ is found, which amounts to about $50 \%$ of the net radiation. This closure gap is by a factor of two outside of the expected error range which we estimate based on the given accuracies and the average flux values (cf. Sect. 3) including the error induced by using the buoyancy flux instead of the true sensible heat flux. The relatively large closure gap might be explained by differences in the footprint areas of the sensors used to measure the components of the surface energy balance (Langer et al., 2011, Sect. 5.1). This is even more likely as a strong spatial variability of the surface and subsurface conditions is observed during the early winter period due to a spatially variable build-up of the snow cover and onset of soil freezing. Surface heterogeneities and inconsistent footprint areas are considered one of the major sources of uncertainty in energy balance studies (e.g. Inagaki et al., 1996; Foken, 2008).

\subsection{Polar winter (1 December-30 January)}

The polar winter section features a highly negative net radiation in the range of -20 to $-25 \mathrm{~W} \mathrm{~m}^{-2}$. Due to polar night conditions, the radiation balance is only determined by thermal radiation. The largest fraction of the radiative loss 

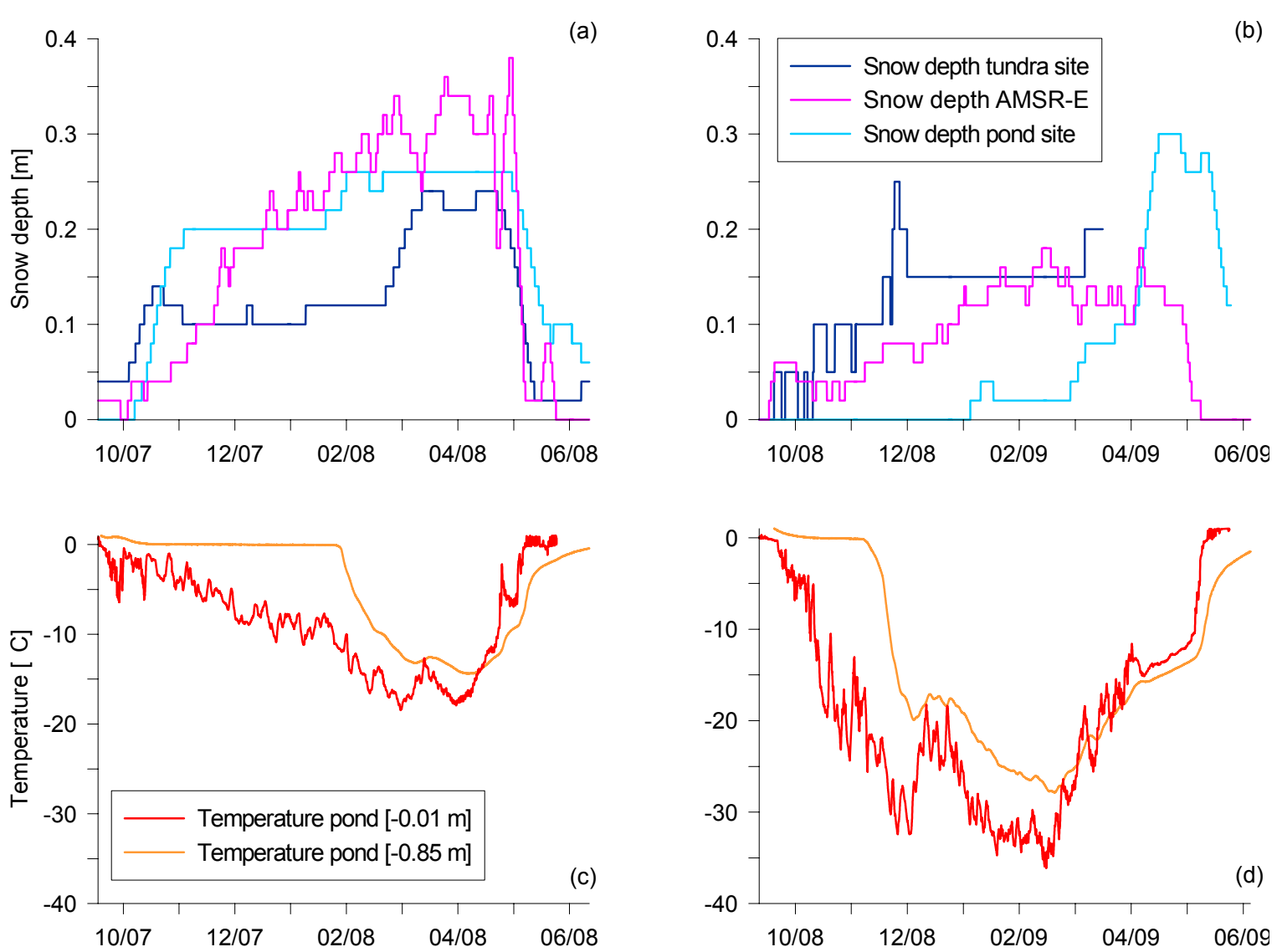

Fig. 4. The diagrams at the top show the evolution of the snow depth measured at the tundra site (polygonal center) and the pond site during the winter periods of (a) 2007 and (b) 2008. Moreover, we depict the snow depth inferred from the AMSR-E snow water equivalent product using a snow density of $190 \mathrm{~kg} \mathrm{~m}^{-3}$ for both periods. The diagrams at the bottom depict the temperatures observed at the surface and the top of sediment of the investigated polygonal pond for the winter periods of (c) 2007 and (d) 2008 .

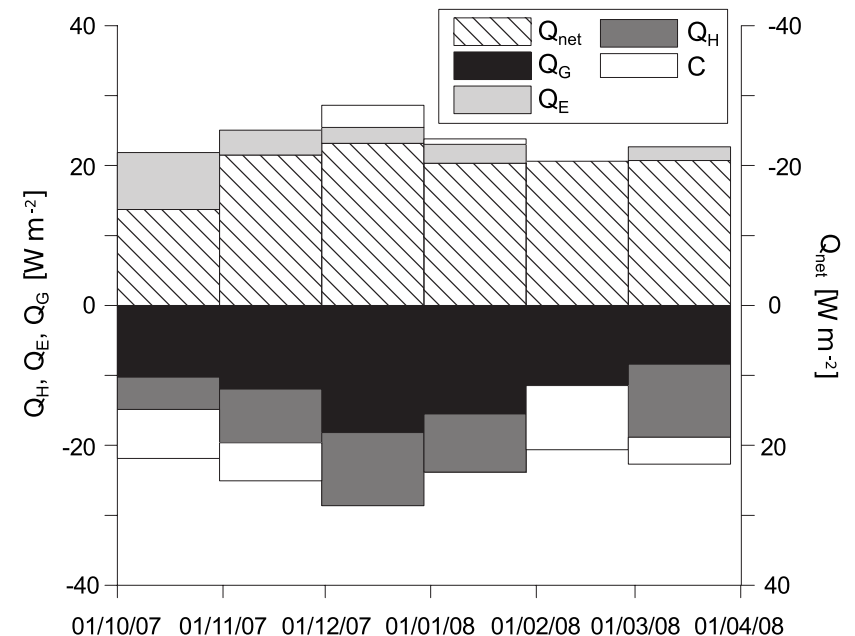

Fig. 5. Monthly averages of energy balance components for the winter 2007/2008. is balanced by the ground heat flux $Q_{\mathrm{G}}$, which is on the order of about $-15 \mathrm{Wm}^{-2}$. Compared to early winter, the sensible heat flux $Q_{\mathrm{H}}$ decreases and is now on the order of $-10 \mathrm{~W} \mathrm{~m}^{-2}$. The latent heat flux $Q_{\mathrm{E}}$ is lowered and features a value of only $4 \mathrm{~W} \mathrm{~m}^{-2}$.

The polar winter section is characterized by the absence of solar radiation during which the air temperatures reach their annual minimum of about $-44^{\circ} \mathrm{C}$ in winter 2007-2008 and $-42^{\circ} \mathrm{C}$ in winter 2008-2009. During winter 2007-2008, the snow cover remains almost constant featuring a depth of about $15 \mathrm{~cm}$ at the tundra surface and about $20 \mathrm{~cm}$ at the polygonal pond. A different evolution of the snow cover is found for 2008-2009, when the snow depth remains between 10 and $15 \mathrm{~cm}$ at the tundra surface, whereas almost no snow cover is detected at the pond. For the winter 2007-2008, freezing continues from early winter into the polar night period. While the remaining unfrozen soil layer is already frozen after a few days, the pond remains partially unfrozen until the end of this section (Fig. 4). This delayed freezing process in 2007-2008 affects the temperature at the bottom of the water body, which is about $15^{\circ} \mathrm{C}$ warmer compared to the following year (Fig. 4). 


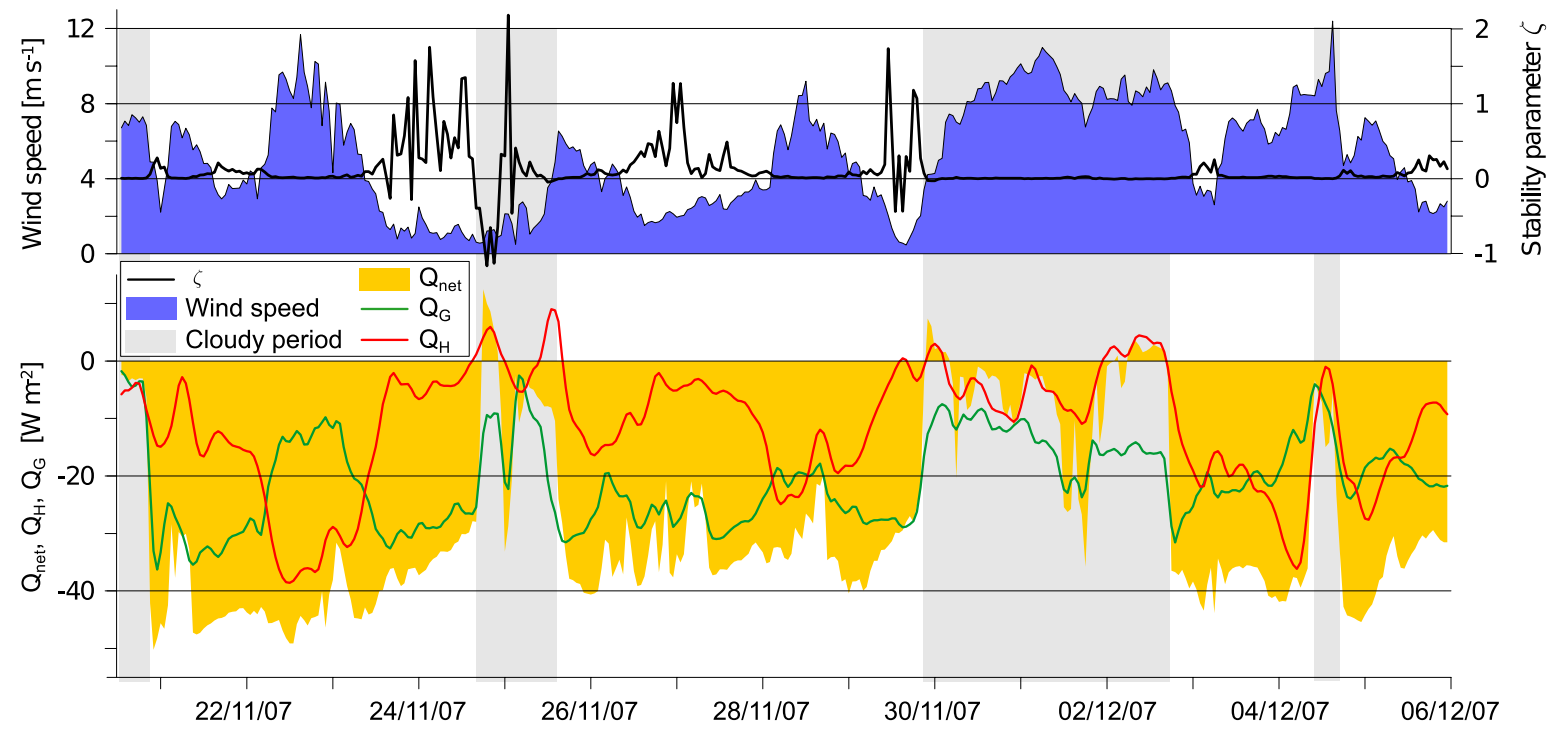

Fig. 6. Hourly averages of $Q_{\text {net }}, Q_{\mathrm{H}}$ and $Q_{\mathrm{G}}$ during the transition from early to polar winter in 2007 (lower graph). Presumably overcast conditions are shaded. Measurements of the wind speed and the stability parameter $\zeta$ are depicted in the upper graph.

The energy balance of the polar winter section is entirely governed by the net long-wave radiation $\Delta Q_{\mathrm{L}}$ which is strongly negative (Table 2). In both years, the incoming long-wave radiation frequently fluctuates between 140 and $240 \mathrm{~W} \mathrm{~m}^{-2}$. Conditions of constant incoming radiation typically last between two and three days. The surface temperatures and thus the outgoing thermal radiation show a strong variability in the range of $-15^{\circ} \mathrm{C}$ to $-45^{\circ} \mathrm{C}$ in both years, which corresponds to emitted radiative fluxes of about -150 and $-250 \mathrm{Wm}^{-2}$. The negative net radiation is partly balanced by a slightly increased sensible heat flux compared to early winter (Table 2, Fig. 5). The largest fraction of the net radiation is balanced by the ground heat flux $Q_{\mathrm{G}}$, which is mainly supplied by the release of sensible heat $Q_{\mathrm{G} \text {,sensible }}$ that originates to about $85 \%$ from the first four meters of the soil column. Recalling the difference in the ground heat flux between early winter 2007 and 2008, the differences are now reversed. The ground heat flux of 2007 is now higher compared to 2008, which corresponds to a warmer soil in 2007 and therefore to a steeper soil temperature gradient.

An exemplary situation during the transition from the early winter to the polar night in 2007-2008 is depicted in Fig. 6. The example shows the typical stepwise pattern of the net long-wave radiation. This pattern is followed by the course of the sensible heat flux and the ground heat flux, which usually balances the largest fraction of the radiative losses. The turbulent heat flux becomes large $\left(Q_{\mathrm{H}} \approx-30 \mathrm{~W} \mathrm{~m}^{-2}\right)$ under clear-sky and windy conditions (wind speed $\approx 8 \mathrm{~m} \mathrm{~s}^{-1}$ ), as they occur around 23 November and 4 December. The negative net radiation is then primarily balanced by the sensible heat flux, which leads to a subsequent surface warming that reduces the snow temperature gradient and thus the ground heat flux (Fig. 6). On rare occasions, the net radiation is found to be positive. During one of these situations, we can observe the development of a slightly unstable stratification $(\zeta<0)$ around 25 November. This situation follows a period of calm conditions featuring stable stratifications and high radiative losses cooling down the near surface atmosphere. The rapid increase of the net radiation to positive values heats up the surface which consequently leads to a positive near-surface temperature gradient and the short-time development of unstable conditions. The unstable stratification breaks down as the net radiation falls back to negative values (Fig. 6).

The dominance of incoming thermal radiation on the surface temperature and thus on the entire energy balance is illustrated in Fig. 7. It can be seen that surface temperature is mainly related to the incoming thermal radiation while other factors, such as wind speed (turbulent exchange) only have a secondary impact. The wind speed reveals its largest impact on the surface temperature during low values of incoming long-wave radiation. This relation is explained by the fact, that the surface cools down strongest under clear-sky conditions when the turbulent heat transport from the atmosphere to the surface is limited by the absence of wind. This situation describes the typical evolution of a near-surface temperature inversion under stable atmospheric stratification $(\zeta>0)$, which leads to pronounced surface cooling. However, such conditions are observed only occasionally, since wind-induced turbulent mixing dominates during the polar night, so that the formation of stable stratifications $(\zeta>0)$ is limited.

Large differences in the ground heat flux between 2007 and 2008 are again observed at the investigated pond 


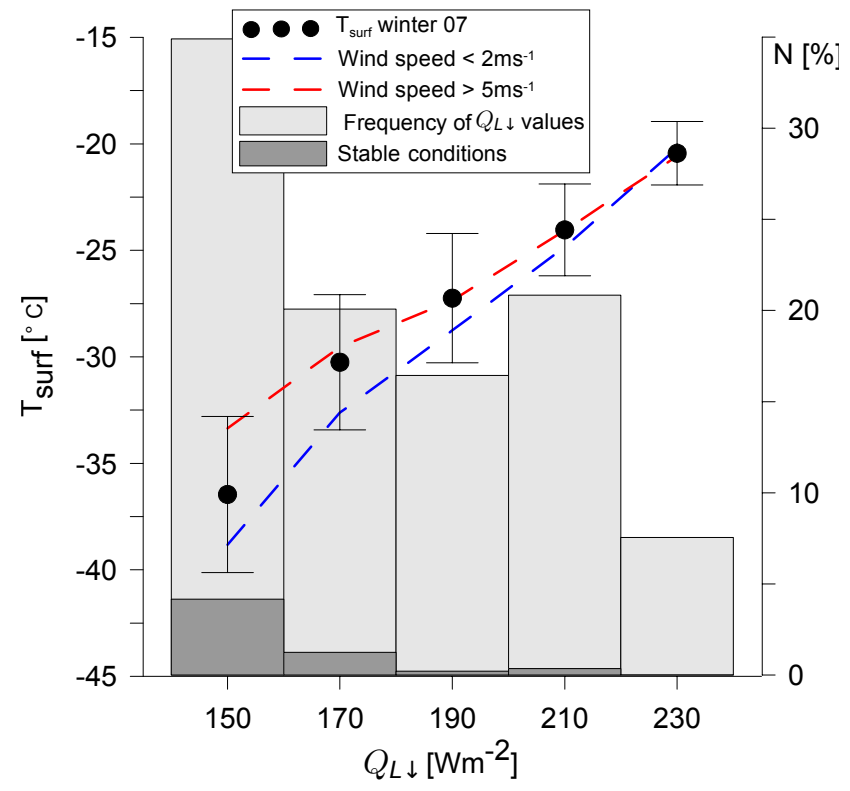

Fig. 7. The surface temperature $T_{\text {surf }}$ in dependence to the incoming long-wave radiation $Q_{\mathrm{L} \downarrow}$ and different wind speeds during the polar winter period 2007. The first histogram (light grey) indicates the frequency of observations that feature the displayed classes of incoming long-wave radiation. The second histogram (dark grey) shows the occurrence of stable atmospheric stratification under the different $Q_{\mathrm{L} \downarrow}$ conditions.

(Table 2), which in 2007-2008 is finally frozen by the end of the polar winter. Similar to the ground heat flux $Q_{\mathrm{G}}$, the pond heat flux $Q_{\mathrm{G}, \mathrm{p}}$ is now higher in 2007-2008 than in 20082009. We also observe that in both years the released energy at the pond $Q_{\mathrm{G}, \mathrm{p}}$ is larger than the radiative losses $Q_{\mathrm{net}, \mathrm{p}}$, which indicates that amplified turbulent sensible heat fluxes might occur at the surface of the frozen water body similar to the early winter period. The ground heat flux at the pond is by a factor of two higher compared to the ground heat flux at the tundra site $Q_{\mathrm{G}}$.

\subsection{Late winter (1 February-30 March)}

The energy balance of the late winter section is still characterized by negative net radiation $Q_{\text {net }}$ of about $-15 \mathrm{~W} \mathrm{~m}^{-2}$, which is still significantly lower compared to the following spring period, described in the companion study. This is due to the fact that the net radiation rapidly increases during this and the following period. The ground heat flux $Q_{\mathrm{G}}$ features about $-5 \mathrm{~W} \mathrm{~m}^{-2}$ and loses its dominant role in balancing the net radiation. The largest fraction of radiative losses is now balanced by a further increased sensible heat flux $Q_{\mathrm{H}}$, which is on the order of $-10 \mathrm{~W} \mathrm{~m}^{-2}$. The modeled latent heat flux $Q_{\mathrm{E}}$ remains small at about $3 \mathrm{~W} \mathrm{~m}^{-2}$.
The synoptic conditions are determined by the end of the polar night and increasing air temperatures from about -35 to $-5^{\circ} \mathrm{C}$. The snow depth in 2008 slightly increases by about 5 to $10 \mathrm{~cm}$ and reaches its annual maximum of 25 to $30 \mathrm{~cm}$.

In the course of the late winter period the net radiation reaches values as low as $-40 \mathrm{~W} \mathrm{~m}^{-2}$, while positive fluxes can exceed $20 \mathrm{~W} \mathrm{~m}^{-2}$ (Fig. 8). Positive net radiation values frequently occur within a pronounced diurnal cycle towards the end of this period. The upwelling long-wave radiation ranges from 160 to $300 \mathrm{~W} \mathrm{~m}^{-2}$ which corresponds to surface temperatures of -40 and $-3{ }^{\circ} \mathrm{C}$, respectively. The sensible heat flux is more negative compared to the polar winter period and balances about $70 \%$ of the radiative losses, while the ground heat flux loses its dominant role. This corresponds to the evolution of a strong temperature gradient in the atmospheric boundary layer, which frequently exceeds values of $-3{ }^{\circ} \mathrm{C}$ with an average gradient of about $-1{ }^{\circ} \mathrm{C}$ (Table 2). The sensible heat flux features a diurnal cycle towards the end of the later winter period and ranges from $-40 \mathrm{~W} \mathrm{~m}^{-2}$ to $5 \mathrm{~W} \mathrm{~m}^{-2}$ (Fig. 8). Positive sensible heat fluxes are usually observed during local noon, when the net radiation is positive due to high values of incoming solar radiation. The atmospheric stratification is neutral during the first half of the late winter section corresponding to high wind speeds. Within the course of the late winter period, the stability parameter $\zeta$ indicates frequent changes between stable and unstable stratifications.

The ground heat flux is mainly supplied by sensible heat from the deep soil layers. About $85 \%$ of the released heat originates from soil cooling down to a depth of $7 \mathrm{~m}$. A more detailed look at the ground heat flux reveals more frequent positive heat fluxes towards the end of the period, which are usually associated with strongly negative sensible heat fluxes. This indicates that at the end of the entire winter period the initial warming of the ground is largely supplied by sensible heat fluxes from the atmosphere. The evolution of the surface energy balance is in good agreement with measurements of the following spring period which are described in the companion study comprising the summer half-year period.

Spatial differences of the energy balance are still observed between the polygonal pond and the tundra site. The ground heat flux at the polygonal pond $Q_{\mathrm{G}, \mathrm{p}}$ is still strongly increased compared to the tundra ground heat flux $Q_{\mathrm{G}}$, which corresponds to the more negative net radiation at the pond $Q_{\text {net,p }}$ (Table 2). This indicates that the polygonal pond most likely features slightly higher surface temperatures. If we assume the surface albedo at the snow covered tundra to be similar to the snow-covered pond, the surface at the pond would be about $1^{\circ} \mathrm{C}$ warmer in accordance to the increased ground heat flux. 


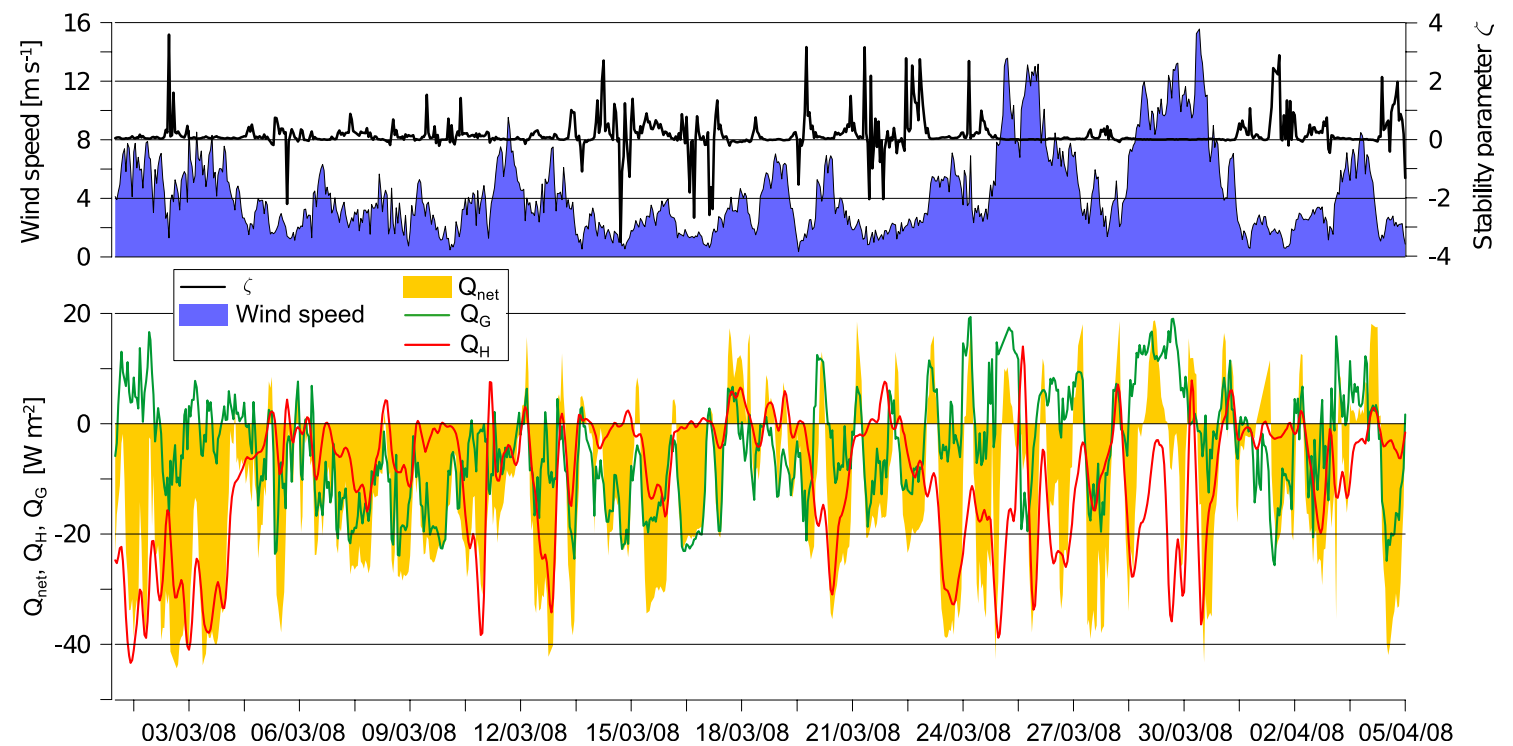

Fig. 8. Hourly averages of $Q_{\mathrm{net}}, Q_{\mathrm{H}}$ and $Q_{\mathrm{G}}$ during the late winter in 2008 (lower graph). The wind speed and the stability parameter $\zeta$ are depicted in the upper graph.

\section{Discussion}

\subsection{The controlling factors of the winter time surface energy balance}

\subsubsection{The long-wave radiation}

The net radiation during the winter period is mainly determined by the long-wave radiation, as it mostly falls within the polar night, while the high albedo of the snow cover limits the role of the short-wave radiation at the beginning and the end of the period (Table 2). The net long-wave radiation fluctuates strongly between almost zero and highly negative values of up to $-50 \mathrm{~W} \mathrm{~m}^{-2}$. The fluctuations are caused by rapid changes of the incoming long-wave radiation which are most likely attributed to changes in cloudiness (Curry et al., 1993; Shupe and Intrieri, 2004). Our measurements indicate that the net radiation sets the general range within which the surface temperature can adjust especially during the polar winter period. Hence, the cloudiness must be considered a dominant factor controlling the evolution of the surface temperature and thus strongly affects the turbulent and ground heat fluxes. The cloudiness is associated with larger-scale atmospheric circulation patterns, such as cyclone activity and the strength of the Siberian High (Brümmer et al., 2000). The impact of atmospheric circulation patterns on the energy balance of the Arctic has been outlined in a number of studies (e.g. Curry et al., 1993; Serreze et al., 2000; Petrone and Rouse, 2000). As the ground heat flux balances the largest fraction of the radiative losses, it is conceivable that the future evolution of the permafrost temperatures is directly influenced by the evolution of winter time cyclone activity at the study site.

\subsubsection{The ground heat flux}

The ground heat flux is of remarkable importance for the surface energy balance during the entire winter, since it is the main balancing factor of the radiative losses. It originates from both the refreezing of the active layer and the cooling of the soil which together sustain a ground heat flux that balances on average about $60 \%$ of the radiative losses. The magnitude of the ground heat flux is attributed to the strong soil temperature gradient caused by the large annual temperature amplitude due to the continental climate condition as well as the shallow snow cover which only constitutes a weak thermal insulation for the ground. Furthermore, the high water (ice) content of the active layer facilitates the storage of energy in the upper soil layer which already balances $30 \%$ of the radiative losses during the entire winter. In addition, the heat conductivity of the frozen soil is by a factor of two higher compared to unfrozen conditions which facilitates a strong conductive heat transport from the deep soil layers to the surface (cf. Langer et al., 2011).

We observe strong differences in the ground heat flux between both years, in particular during the early winter period when the ground heat flux in 2007 is by a factor of two smaller compared to 2008 . This is most likely attributed to the faster snow cover build-up in 2007 and higher radiative losses in 2008 leading to a delayed soil freezing of about a week in 2007 compared to 2008. At the investigated pond, where almost no snow cover is observed during the early winter period in 2008 , the refreezing is even delayed by about three months. Our measurements demonstrate that the time that is required for completely freezing the tundra soils and ponds is highly sensitive to the evolution of the snow cover 
and the downwelling long-wave radiation which is largely controlled by cloudiness.

\subsubsection{The sensible heat flux}

While the interplay between the net radiation, the ground heat flux and the sensible heat flux can be complex (Fig. 6), the magnitude of the average sensible heat flux is significantly smaller than the ground heat flux during most of the winter period. The predominantly high wind speeds and neutral atmospheric stratifications suggest that the sensible heat flux is not limited by the turbulent transport. Its contribution to the surface energy balance is most likely limited by the depleted atmospheric heat reservoir under the continental conditions which is also reflected in the extremely cold air temperatures. The strong ground heat flux is potentially a limiting factor for the further cooling of the near-surface atmosphere, as the heat reservoir in the ground can deliver most of the energy lost through long-wave radiation at the surface. The contribution of the winter time sensible heat flux to the surface energy balance is by a factor of two smaller than values reported for arctic-oceanic conditions on Svalbard (Westermann et al., 2009), but of similar magnitude as values reported from measurements on sea ice at the Arctic Ocean (Persson et al., 2002).

The highest values of sensible heat fluxes are observed at the end of the winter season when the ground heat flux loses its dominant role. The measurements reveal that at the end of the late winter period the sensible heat flux contributes substantially to the initial warming of the soil. These findings are in good agreement with observations immediately before the onset of snow melt in spring (Langer et al., 2011), which suggests that the warming of the soil as well as the following snow melt is at least partly triggered by the influx of warm air masses, which lead to a warming of the cold tundra surfaces. This might be attributed to the attenuation of the Siberian High which falls within this time and is observed to lead to an increased cyclone activity in northern Siberia (Serreze et al., 1993; Zhang et al., 2004).

\subsection{The annual surface energy balance}

The extensive dataset presented in this and the companion paper (Langer et al., 2011) allows to assess the annual course of the surface energy balance at least in a semi-quantitative way, despite of measurement uncertainties and gaps in the time series due to instrument failure.

The net radiation during the summer season is largely determined by the incoming short-wave radiation, which is further intensified by the polar day conditions. Conversely, the net radiation during winter is almost entirely determined by long-wave radiation facilitated by low or zero values of the short-wave radiation and the high albedo of the snow cover. In both periods, the net radiation is strongly altered by the presence of clouds. Our observations suggest that the net ra- diation is attenuated during the high summer season by the presence of clouds, while the radiative losses are reduced during the entire winter period. This is in agreement with more detailed observations of the cloud radiative forcing in the Arctic (Shupe and Intrieri, 2004).

During the winter period, the largest fraction of the net radiation is provided by the ground heat flux. The average ground heat flux of the winter half-year period ranges from -11 to $-15 \mathrm{~W} \mathrm{~m}^{-2}$ and from 11 and $13 \mathrm{~W} \mathrm{~m}^{-2}$ during the summer season (Langer et al., 2011). Despite the fact that the radiative forcing during winter is considerably lower than in the summer season, the ground heat flux is of a similar magnitude (Fig. 9). This indicates that the ground heat budget is in equilibrium in terms of the expected measurement accuracy.

During the winter period, an average latent heat flux of about $5 \mathrm{~W} \mathrm{~m}^{-2}$ is observed which is equivalent to a total of $30 \mathrm{~mm}$ of sublimated water which is about $60 \%$ of the water equivalent of the snow cover at the end of winter. Although the contribution to the surface energy balance is low, the winter time latent heat flux has a large impact on the hydrology of study site, since the snow cover contributes about a quarter to the annual water budget (Langer et al., 2011). The annual average of the latent heat flux is about $15 \mathrm{~W} \mathrm{~m}^{-2}$, corresponding to $190 \mathrm{~mm}$ of evaporated water. This equates to about 70 to $80 \%$ of the total annual precipitation reported for the study site (Boike et al., 2008), so that the vertical water balance is positive.

Over the entire winter period we observe an average sensible heat flux of about $-8 \mathrm{~W} \mathrm{~m}^{-2}$ which amounts to a cooling of an air column of $1000 \mathrm{~m}$ height by about $30^{\circ} \mathrm{C}$ over a period of 6 months. This matches the order of magnitude of the observed near-surface temperature cooling, which is also on the order of $30^{\circ} \mathrm{C}$. The average sensible heat flux during the summer half-year period is approximately 6 to $7 \mathrm{~W} \mathrm{~m}^{-2}$ (Langer et al., 2011), which indicates that the annual heat budget of the atmosphere is almost in equilibrium in the course of one year. This indicates that heat advection plays only a secondary role in the annual energy budget, although heat advection is found to be an important factor for processes such as snow melt and initial warming in Siberia (Iijima et al., 2007).

The annual overview indicates that the surface energy balance is almost in equilibrium for the sensible and the ground heat flux. Hence, the gain of radiative energy mainly during the summer season is almost entirely balanced by the latent heat flux. The total evaporation is also in a good agreement with the precipitation which is only slightly larger. Therefore, it is conceivable that the horizontal exchange of energy and water is very limited at the study site. This corresponds to the strong intensity of water recycling observed in northeast Siberia (Trenberth, 1999; Serreze et al., 2002). 
(a)

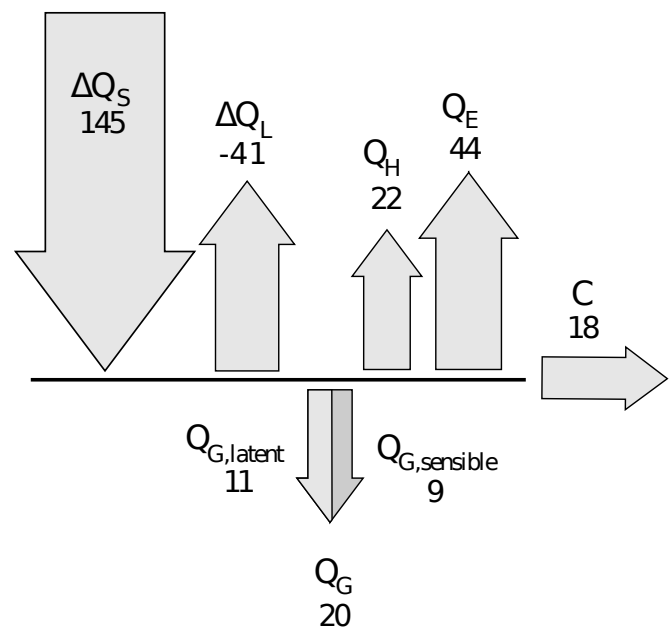

(b)

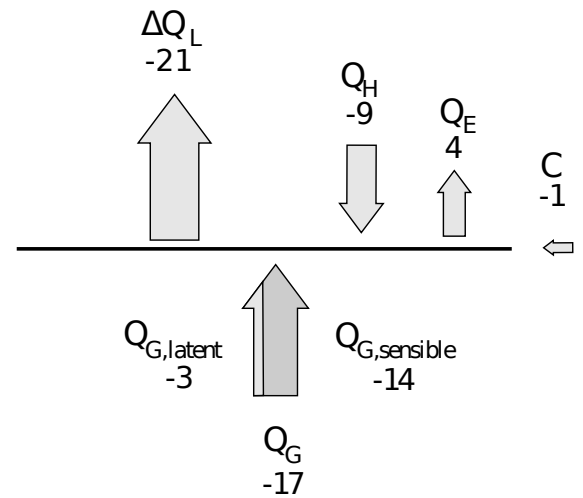

Fig. 9. The partitioning of the surface energy balance during (a) the summer period from 7 June 2008 to 30 August 2008 (cf. Langer et al., 2011) and (b) the winter period from 1 December 2007 to 30 January 2008 (Table 2). The areas of the arrows are scaled according to the heat flux values. The ground heat flux at the tundra site $Q_{\mathrm{G}}$ is separated according to the internal energy storage into sensible $Q_{\mathrm{G}}$,sensible and latent heat $Q_{\mathrm{G}, \text { latent }}$.

\subsection{Implications for modeling permafrost-snow- atmosphere interactions}

As stated in the most recent implementation plan of the "World Climate Research Programme", it "is essential to continue the development and validation of physically based land-atmosphere-cryosphere process models, including permafrost-hydrology and carbon cycle interactions, with appropriate complexity for their use in coupled climate models across a range of time and space scales" (WCRP, 2010). Nevertheless, comprehensive field datasets that could be employed for this task are extremely sparse in the Arctic. To date, the study on the surface energy budget presented in this and the companion paper (Langer et al., 2011) represents the only effort of that scope conducted in the vast permafrost areas of northern Siberia. Being so, it is appropriate to draw qualitative conclusions for modeling permafrostsnow-atmosphere interactions on different scales:

- The ground heat flux at the study site is of remarkable magnitude, especially during the long-lasting arctic winter. Between October and March, the ground heat flux supplied by the refreezing active layer and the cooling of a soil column to a depth of $15 \mathrm{~m}$ provides about $60 \%$ of the energy lost by net radiation. The ground heat flux must therefore be regarded a key factor in the formation of the surface temperature and thus for the radiation balance and the near-surface air temperature. It should be verified whether the simplified representation of soil thermal processes in land-surface schemes employed by climate models is adequate for permafrost areas, which occupy about $25 \%$ of the land area of the Northern Hemisphere (Brown et al., 1997). It has been demonstrated that the chosen soil parameterization can affect the performance of climate models (Pitman, 2003; Rinke et al., 2008; Lawrence and Slater, 2008). By incorporating freezing of soil water, the representation of the boundary layer dynamics in weather and climate models was improved (Viterbo et al., 1999; Cox et al., 1999), Beesley et al. (2000) could relate inaccuracies of the near-surface air temperature in weather forecast models to the parameterization of the ground heat flux.

- Our measurements have demonstrated a high degree of small-scale heterogeneity of important processes, particularly during the refreezing of the active layer. Differences in completion of freeze-back between water bodies and soil can amount up to several months and the duration of refreezing in different years can vary up to three months. For the development of Earth System Models aiming to predict greenhouse gas emissions from permafrost areas (Khvorostyanov et al., 2008), this presents an additional challenge, as the soil volume, in which microbial decomposition can take place, is highly variable in time and space. While the significance of larger water bodies, such as thermokarst lakes, for methane emissions has been recognized by Walter et al. (2006, 2007), small ponds showing a delayed refreezing compared to the surrounding tundra soils might be of similar importance, as they are frequent landscape elements in polygonal tundra regions. In order to account for such subgrid variability in larger-scale modeling approaches, a focus of future research should be put 
on the development of up- and downscaling algorithms for the governing processes and variables.

\section{Conclusions}

We present measurements of the winter time surface energy balance on Samoylov Island in the Lena River Delta in northern Siberia. The study facilitates understanding the processes governing energy and moisture turnover in the coupled permafrost-snow-atmosphere system in a quantitative way. It is based on a data set comprising all components of the surface energy balance at hourly resolution over about two years (see also Langer et al., 2011), which is one of the few data sets that could be employed to validate and improve land-surface schemes in atmospheric circulation models for the vast tundra regions in Siberia. The main findings are:

- The largest fraction (60\%) of the radiative losses during the winter season is balanced by the ground heat flux. This is facilitated by a shallow snow cover, a strong soil temperature gradient in conjunction with the relatively large thermal conductivity of the frozen peat soil, and the large amount of latent heat which is stored in the thawed active layer. At a freezing pond, the ground heat flux delivers an even larger fraction $(80 \%)$ of the net radiation.

- The sensible heat flux balances only about $40 \%$ of the net radiation and thus is of secondary importance during most of the winter period, despite of strong turbulent atmospheric exchange due to frequent high wind speeds and relatively rare stable atmospheric stratifications.

- The latent heat flux is almost negligible for the surface energy balance during the winter season. However, the sublimation of snow corresponds to an water equivalent of about $60 \%$ of the snow cover at the end of the winter period. This makes the winter time sublimation an important factor in the annual water budget.

- The timing of the refreezing of the investigated pond is highly sensitive to the snow depth on top of the ice surface and the incoming long-wave radiation which is mainly determined by cloudiness. Measurements in two consecutive years reveal a difference of about three months in the time required to freeze to the bottom.

We conclude that further energy balance studies over the annual cycle across a variety of high-latitude ecosystems are highly desirable in order to improve models and thus climate projections for the Arctic.

\section{Appendix A}

\section{Definitions and constants}

$Q_{\text {net }}$
$\Delta Q_{\mathrm{S}}$
$\Delta Q_{\mathrm{L}}$
$Q_{\mathrm{L} \downarrow}$
$Q_{\mathrm{H}}$
$Q_{\mathrm{HB}}$
$Q_{\mathrm{E}}$
$Q_{\mathrm{G}}$
$Q_{\mathrm{G}, \text { sensible }}$
$Q_{\mathrm{G}, \text { latent }}$
$Q_{\text {net,p }}$
$Q_{\mathrm{G}, \mathrm{p}}$
$Q_{\mathrm{melt}}$
$C$
$u_{*}$
$\zeta=z / L_{*}$
$z$
$L_{*}$
$T_{\text {air }}$
$T_{\text {surf }}$
$\mathrm{RH}$
$\theta_{\mathrm{w}}$
$\theta_{\mathrm{w}, \min }$
$\theta_{\mathrm{w}, \mathrm{max}}$
$\theta_{\mathrm{i}}$
$P_{\text {dry }}$
$\rho_{\text {ice }}=0.91 \mathrm{~g} \mathrm{~cm}^{-3}$
$\rho_{\text {snow }}=0.19 \mathrm{~g} \mathrm{~cm}^{-3}$
$D_{\mathrm{h}}$
$K_{\mathrm{h}}$
$C_{\mathrm{h}}$
$C_{\mathrm{h}, \mathrm{i}}=1.9 \mathrm{MJ} \mathrm{m}^{-3} \mathrm{~K}^{-1}$
$C_{\mathrm{h}, \mathrm{s}} \approx 2.3 \mathrm{MJ} \mathrm{m}^{-3} \mathrm{~K}^{-1}$

net radiation

net short-wave radiation net long-wave radiation incoming long-wave radiation sensible heat flux buoyancy flux latent heat flux ground or snow heat flux sensible ground heat flux latent ground heat flux net radiation at the pond heat flux released from pond heat flux consumed by melting snow residual of the energy balance friction velocity stability parameter measurement height Obukhov length air temperature surface temperature relative humidity volumetric liquid water content minimum liquid water content (frozen) maximum liquid water content (thawed) volumetric ice content porosity density of ice density of snow thermal diffusivity thermal conductivity volumetric heat capacity volumetric heat capacity of ice volumetric heat capacity of the solid soil matrix

Acknowledgements. We are thankful to the Department of MicroMeteorology of the University of Bayreuth headed by Thomas Foken for providing the eddy covariance post-processing software. We especially acknowledge the help of Günther Stoof for the support of our field work especially during the spring expeditions. We gratefully acknowledge financial support by the Helmholtz Association through a grant (VH-NG 203) awarded to Julia Boike.

Edited by: M. Stendel

\section{References}

ACIA: Impacts of a Warming Arctic - Arctic Climate Impact Assessment, vol. 1, Cambridge University Press, Cambridge, UK, 2004.

Beesley, J., Bretherton, C., Jakob, C., Andreas, E., Intrieri, J., and Uttal, T.: A comparison of cloud and boundary layer variables in the ECMWF forecast model with observations at Surface Heat Budget of the Arctic Ocean (SHEBA) ice camp, J. Geophys. Res., 105, 12337-12349, 2000. 
Boike, J., Wille, C., and Abnizova, A.: Climatology and summer energy and water balance of polygonal tundra in the Lena River Delta, Siberia, J. Geophys. Res.-Biogeo., 113, G03025, doi:10.1029/2007JG000540, 2008.

Brotzge, J. and Duchon, C.: A field comparison among a domeless net radiometer, two four-component net radiometers, and a domed net radiometer, J. Atmos. Ocean. Tech., 17, 1569-1582, 2000.

Brown, J., Ferrians Jr., O., Heginbottom, J., and Melnikov, E.: Circum-Arctic map of permafrost and ground-ice conditions, US Geological Survey Circum-Pacific Map, 1997.

Brümmer, B., Thiemann, S., and Kirchgäßner, A.: A cyclone statistics for the Arctic based on European Centrere-analysis data, Meteorol. Atmos. Phys., 75, 233-250, 2000.

Bugbee, B., Droter, M., Monje, O., and Tanner, B.: Evaluation and modification of commercial infra-red transducers for leaf temperature measurement, Adv. Space Res., 22, 1425-1434, 1998.

Cox, P., Betts, R., Bunton, C., Essery, R., Rowntree, P., and Smith, J.: The impact of new land surface physics on the GCM simulation of climate and climate sensitivity, Clim. Dynam., 15, 183203, 1999.

Curry, J., Schramm, J., and Ebert, E.: Impact of clouds on the surface radiation balance of the Arctic Ocean, Meteorol. Atmos. Phys., 51, 197-217, 1993.

Dozier, J. and Warren, S.: Effect of viewing angle on the infrared brightness temperature of snow, Water Resour. Res., 18, 14241434, 1982.

ESA: Envisat (MERIS) image of the Lena River Delta, http://earth. eo.esa.int/cgi-bin/satimgsql.pl?show_url=1471, access: 30 May 2011, 2006.

Foken, T.: The energy balance closure problem - An overview, Ecol. Appl., 18, 1351-1367, 2008.

Foster, J., Sun, C., Walker, J., Kelly, R., Chang, A., Dong, J., and Powell, H.: Quantifying the uncertainty in passive microwave snow water equivalent observations, Remote Sens. Environ., 94, 187-203, 2005.

Grigoriev, N.: The temperature of permafrost in the Lena delta basin - deposit conditions and properties of the permafrost in Yakutia, chap. 2, 97-101, Yakutsk, 1960 (in Russian).

Høgstrøm, U.: Non-dimensional wind and temperature profiles in the atmospheric surface layer: A re-evaluation, Bound.-Lay. Meteorol., 42, 55-78, 1988.

Iijima, Y., Masuda, K., and Ohata, T.: Snow disappearance in Eastern Siberia and its relationship to atmospheric influences, Int. J. Climatol., 27, 169-178, 2007.

Inagaki, A., Letzel, M., Raasch, S., and Kanda, M.: Impact of surface heterogeneity on energy balance: A study using LES, J. Meteorol. Soc. Jpn., 84, 187-198, 1996.

Johannessen, O., Bengtsson, L., Miles, M., Kuzmina, S., Semenov, V., Alekseev, G., Nagurnyi, A., Zakharov, V., Bobylev, L., Pettersson, L., Hasselmann, K., and Cattle, H.: Arctic climate change: observed and modelled temperature and sea-ice variability, Tellus A, 56, 328-341, 2004.

Kelly, R., Chang, A., Foster, J., and Tedesco, M.: AMSR-E/Aqua 5-day 3 Global Snow Water Equivalent EASE-Grids V002, Boulder, Colorado USA: National Snow and Ice Data Center, Digital media, [data used from 2007-2009], 2004.

Khvorostyanov, D., Krinner, G., Ciais, P., Heimann, M., and Zimov, S.: Vulnerability of permafrost carbon to global warming. Part I: model description and role of heat generated by organic matter decomposition, Tellus B, 60, 250-264, 2008.

Kohsiek, W., Liebethal, C., Foken, T., Vogt, R., Oncley, S., Bernhofer, C., and Debruin, H.: The Energy Balance Experiment EBEX-2000. Part III: Behaviour and quality of the radiation measurements, Bound.-Lay. Meteorol., 123, 55-75, 2007.

Langer, M., Westermann, S., Muster, S., Piel, K., and Boike, J.: The surface energy balance of a polygonal tundra site in northern Siberia - Part 1: Spring to fall, The Cryosphere, 5, 151-171, doi:10.5194/tc-5-151-2011, 2011.

Lawrence, D. and Slater, A.: A projection of severe near-surface permafrost degradation during the 21 st century, Geophys. Res. Lett, 32, L24401, doi:10.1029/2005GL025080, 2005.

Lawrence, D. and Slater, A.: Incorporating organic soil into a global climate model, Clim. Dynam., 30, 145-160, 2008.

Lawrence, D., Slater, A., Romanovsky, V., and Nicolsky, D.: Sensitivity of a model projection of near-surface permafrost degradation to soil column depth and representation of soil organic matter, J. Geophys. Res, 113, F02011, doi:10.1029/2007JF000883, 2008.

Lewkowicz, A.: Evaluation of miniature temperature-loggers to monitor snowpack evolution at mountain permafrost sites, northwestern Canada, Permafrost Periglac., 19, 323-331, 2008.

Liu, H., Peters, G., and Foken, T.: New equations for sonic temperature variance and buoyancy heat flux with an omnidirectional sonic anemometer, Bound.-Lay. Meteorol., 100, 459-468, 2001.

Mauder, M. and Foken, T.: Documentation and instruction manual of the eddy covariance software package TK2, Univ. of Bayreuth, Dept. of Mikrometeorology, 2004.

Mauder, M., Liebethal, C., Göckede, M., Leps, J. P., Beyrich, F., and Foken, T.: Processing and quality control of flux data during LITFASS-2003, Bound.-Lay. Meteorol., 121, 67-88, 2006.

Mauder, M., Foken, T., Clement, R., Elbers, J. A., Eugster, W., Grünwald, T., Heusinkveld, B., and Kolle, O.: Quality control of CarboEurope flux data - Part 2: Inter-comparison of eddy-covariance software, Biogeosciences, 5, 451-462, doi:10.5194/bg-5-451-2008, 2008.

Moritz, R., Bitz, C., and Steig, E.: Dynamics of recent climate change in the Arctic, Science, 297, 1497-1502, doi:10.1126/science.1076522, 2002.

Nicolsky, D., Romanovsky, V., Alexeev, V., and Lawrence, D.: Improved modeling of permafrost dynamics in a GCM land-surface scheme, Geophys. Res. Lett., 34, L08501, doi:10.1029/2007GL029525, 2007.

Obleitner, F. and De Wolde, J.: On intercomparison of instruments used within the Vatnajökull glacio-meteorological experiment, Bound.-Lay. Meteorol., 92, 25-35, 1999.

Osterkamp, T.: The recent warming of permafrost in Alaska, Global and Planet. Change, 49, 187-202, 2005.

Persson, P., Fairall, C., Andreas, E., Guest, P., and Perovich, D.: Measurements near the Atmospheric Surface Flux Group tower at SHEBA: Near-surface conditions and surface energy budget, J. Geophys. Res.-Oceans, 107, 8045, doi:10.1029/2000JC000705, 2002.

Petrone, R. and Rouse, W.: Synoptic controls on the surface energy and water budgets in sub-arctic regions of Canada, Int. J. Climatol., 20, 1149-1165, 2000.

Pitman, A.: The evolution of, and revolution in, land surface schemes designed for climate models, Int. J. Climatol., 23, 
479-510, 2003.

Pulliainen, J. and Hallikainen, M.: Retrieval of regional snow water equivalent from space-borne passive microwave observations, Remote Sens. Environ., 75, 76-85, 2001.

Rinke, A., Kuhry, P., and Dethloff, K.: Importance of a soil organic layer for Arctic climate: A sensitivity study with an Arctic RCM, Geophys. Res. Lett., 35, L13709, doi:10.1029/2008GL034052, 2008.

Schotanus, P., Nieuwstadt, F., and Bruin, H.: Temperature measurement with a sonic anemometer and its application to heat and moisture fluxes, Bound.-Lay. Meteorol., 26, 81-93, 1983.

Serreze, M., Box, J., Barry, R., and Walsh, J.: Characteristics of Arctic synoptic activity, 1952-1989, Meteorol. Atmos. Phys., 51, 147-164, 1993.

Serreze, M., Walsh, J., Chapin, F., Osterkamp, T., Dyurgerov, M., Romanovsky, V., Oechel, W., Morison, J., Zhang, T., and Barry, R.: Observational evidence of recent change in the northern highlatitude environment, Climatic Change, 46, 159-207, 2000.

Serreze, M., Bromwich, D., Clark, M., Etringer, A., Zhang, T., and Lammers, R.: Large-scale hydro-climatology of the terrestrial Arctic drainage system, J. Geophys. Res., 107, 8160, doi:10.1029/2001JD000919, 2002.

Shupe, M. D. and Intrieri, J. M.: Cloud Radiative Forcing of the Arctic Surface: The Influence of Cloud Properties, Surface Albedo, and Solar Zenith Angle, J. Climate, 17, 616-628, doi:10.1175/1520-0442(2004)017<0616:CRFOTA > 2.0.CO;2, 2004.

Stendel, M. and Christensen, J.: Impact of global warming on permafrost conditions in a coupled GCM, Geophys. Res. Lett., 29, 1632, doi:10.1029/2001GL014345, 2002.
Tjernstrom, M., Zagar, M., Svensson, G., Cassano, J., Pfeifer, S., Rinke, A., Wyser, K., Dethloff, K., Jones, C., Semmler, T., and Shaw, M.: Modelling the arctic boundary layer: an evaluation of six ARCMIP regional-scale models using data from the SHEBA project, Bound.-Lay. Meteorol., 117, 337-381, 2005.

Trenberth, K.: Atmospheric moisture recycling: role of advection and local evaporation, J. Climate, 12, 1368-1381, 1999.

Viterbo, P., Beljaars, A., Mahfouf, J., and Teixeira, J.: The representation of soil moisture freezing and its impact on the stable boundary layer, Q. J. Roy. Meteor. Soc., 125, 2401-2426, 1999.

Walter, K., Zimov, S., Chanton, J., Verbyla, D., and Chapin, F.: Methane bubbling from Siberian thaw lakes as a positive feedback to climate warming, Nature, 443, 71-75, 2006.

Walter, K., Edwards, M., Grosse, G., Zimov, S., and Chapin III., F.: Thermokarst lakes as a source of atmospheric $\mathrm{CH}_{4}$ during the last deglaciation, Science, 318, 633-636, doi:10.1126/science.1142924, 2007.

WCRP: World Climate Research Programme Implementation Plan 2010-2015, http://www.wmo.ch/pages/prog/wcrp/documents/ WCRP_IP_2010_2015.pdf, access: 7 June 2011, 2010.

Westermann, S., Lüers, J., Langer, M., Piel, K., and Boike, J.: The annual surface energy budget of a high-arctic permafrost site on Svalbard, Norway, The Cryosphere, 3, 245-263, doi:10.5194/tc3-245-2009, 2009.

Zhang, X., Walsh, J. E., Zhang, J., Bhatt, U. S., and Ikeda, M.: Climatology and Interannual Variability of Arctic Cyclone Activity: 1948-2002, J. Climate, 17, 2300-2317, doi:10.1175/15200442(2004)017<2300:CAIVOA > 2.0.CO;2, 2004. 